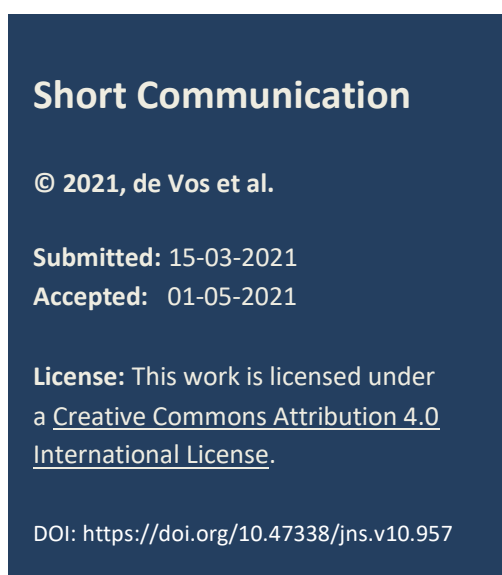

\section{A formal support group for esophageal atresia and/or tracheoesophageal fistula in South Africa may improve the outcome of these children and their families}

\author{
Corné de Vos, ${ }^{* 1,2}$ Werner de Vos, ${ }^{3}$ Daniel Sidler, ${ }^{2}$ \\ 1 Tygerberg Children's Hospital, Cape Town, South Africa \\ 2 Division of Paediatric Surgery, University of Stellenbosch, Cape Town, South Africa \\ 3 Division of Surgery, University of Stellenbosch, Cape Town, South Africa
}

Correspondence*: Dr. Corné de Vos, MBCHB, MMED Paed Surg (US), FC Paed Surg (SA), Tygerberg Children's Hospital, Franci van Zyl Road, Division of Paediatric Surgery, Ward G4, 4th Floor, Tygerberg, Cape Town, South Africa, 7505. E-mail: cdevos@sun.ac.za

\section{KEYWORDS \\ Esophageal atresia, \\ Support groups \\ Quality of life, \\ Tracheoesophageal fistula}

\begin{abstract}
The psychosocial aspect of various congenital anomalies like esophageal atresia (EA) with/or without a tracheoesophageal fistula (TEF) being the cause of Post-traumatic stress disorder (PTSD), depression, and anxiety in parents of these children, is often overlooked by medical professionals. Support groups may be useful to address a part of this problem and form an important aspect of emotional support for any rare or congenital disease. A cross-sectional descriptive study was conducted to assess the need for a formal support group for parents of patients born with EA and to emphasize the role of emotional support for these parents and children. A questionnaire was sent to members of an informal WhatsApp group which included participants with diverse demographics across private and public platforms, across South Africa. The questions focused on 3 main areas: demographic data, diagnosis and the surgery, and information about the participant's emotional support. All the data were inserted in an excel datasheet and descriptive statistical analysis was used. Questions were sent to 14 members of an informal WhatsApp group. Eight were included in the study. All 8 participants were mothers of children born with an EA with a TEF. The questions about the need for emotional support focus on the time after the baby was born. The majority (87.5\%) of the mothers felt that they could bond with their babies during pregnancy, but in contrast, $75 \%$ felt that they missed an opportunity to bond with their babies after birth, mainly because they were not allowed to hold their babies for up to 11 days after birth. Only 1 of the mothers were in contact with other families with children born with EA, and 6 of the remaining 7 agreed that this would have helped them during this emotionally challenging time. All 8 thought that sharing their stories with others could have helped them emotionally and all agreed that an EA/TEF support group was a good idea. The family, as another patient, ought to be treated and included in the overall treatment plan if we aim to improve the quality of life for both the patients and their families. Disease-specific support groups can play a major role in the emotional well-being of both the children born with EA and their families.
\end{abstract}

The epidemiology, surgical management, and biological outcome of esophageal atresia (EA) with or without a tracheoesophageal fistula (TEF) are well known. The psychosocial aspect of this disease being the cause of Post-traumatic stress disorder (PTSD), depression, and anxiety in parents of these children is often overlooked by pediatric surgeons.[1] As two medical doctors (a family practitioner and a pediatric surgeon) and the parents of a child born with a rare type of EA, we felt the need to explore the nonmedical side of this disease and the need for a more formal support system. According to a paper published in 2014, volunteer support groups seemed to offer social benefits through reducing isolation, increasing social networks, and building empathetic relationships.[2] We would suggest that it is safe to assume that support groups could be of value in the support of families and caregivers of children suffering from rare or congenital diseases. The aim of this study was to emphasize the role of emotional support for parents with children born with all types of esophageal atresia (EA) and to assess the need for a formal support group for these parents in South Africa.

After HREC approval was granted (N19/02/028) a cross-sectional descriptive study was conducted. 
Questions (Table 1 \& Table 2) were sent to members of an informal WhatsApp group that included participants with diverse demographics across private and public platforms, across South Africa. Informed consent accompanied the questions and had to be completed as part of the inclusion criteria. Questions were sent via WhatsApp or email and were completed by the participants. The questions focused on 3 main areas: (1) demographic data, (2) information about the diagnosis and the surgery, and (3) the emotional sup- port which was provided to the participants during the neonatal period and after the surgery. No openended questions were included. All completed questions that were accompanied by completed informed consent, were included in the study. All the data were inserted in an excel datasheet. Descriptive statistical analysis was used. Unique identifiers were used, and personal identifiers were only known to the principal investigator.

Table 1: Demographic data and general information

\begin{tabular}{|c|c|c|}
\hline \multicolumn{3}{|c|}{ DEMOGRAPHIC DATA } \\
\hline Details of baby born with EA/TEF & Sex & Date of birth \\
\hline & Public or private sector & \\
\hline & Gestational age at birth & \\
\hline & Age when the diagnosis was made (days) & \\
\hline \multirow[t]{2}{*}{ Details of parent answering the questions } & Mother/Father & Age at time of baby's birth \\
\hline & $\begin{array}{l}\text { How many siblings did the baby have at } \\
\text { home? }\end{array}$ & \\
\hline \multicolumn{3}{|c|}{ INFORMATION ABOUT THE DIAGNOSIS AND SURGERY } \\
\hline Antenatal (your pregnancy) & $\begin{array}{l}\text { Did the doctors suspect anything while you } \\
\text { were pregnant? }\end{array}$ & $\begin{array}{l}\text { If YES, how far along were you when they } \\
\text { first suspected something? }\end{array}$ \\
\hline \multirow[t]{2}{*}{ Details about the birth of your baby } & $\begin{array}{l}\text { Was the baby born early (prem) or on the } \\
\text { right time (term)? }\end{array}$ & \\
\hline & $\begin{array}{l}\text { Was it a planned normal delivery or an } \\
\text { emergency normal delivery? }\end{array}$ & $\begin{array}{l}\text { Was it a planned cesarean section or an } \\
\text { emergency cesarean section? }\end{array}$ \\
\hline \multirow[t]{2}{*}{ What type of EA did your baby have? } & OA only & $\mathrm{OA}$ and TOF \\
\hline & H-type TOF & \\
\hline VACTERL & $\begin{array}{l}\text { Does your baby have any other } \\
\text { abnormalities? }\end{array}$ & \\
\hline
\end{tabular}

Questions were sent to 14 members of an informal WhatsApp group. Several efforts were made to encourage members of the group to answer and return the questions but in the end, only 8 of the fourteen $(57 \%)$ participants answered the questions and returned it with signed informed consent. All 8 participants were mothers of children born with esophageal atresia (EA) with a TEF. All children were born between 2009 and 2017 with an average gestational age of 35.7 weeks (31-38 weeks). Incidentally, all 8 children of mothers who completed the survey were males. The age of the mothers at the birth of their children were all between $20-40$ years. Five of the 8 $(62.5 \%)$ children had their surgery in the private sector in South Africa. Fifty percent of the participants had other children at home, one of which was a twin sister born healthy and without EA.

Three of the participants had antenatal ultrasounds which were suspicious for EA (polyhydramnios with no stomach bubble), but the diagnosis was only confirmed after birth. Six of the participants had cesarean sections, 4 of which were emergency procedures. The reason for emergency cesarean sections was not explored as part of our questions but it was most likely due to fetal distress in mostly premature babies. In $62.5 \%$ of patients, there was no antenatal suspicion of EA and all diagnoses were confirmed immediately after birth.

The questions about the need for emotional support (Table 3) focus on the time after the baby was born. Only 1 of the participants could sleep next to her baby in the NICU. Six of the eight participants said that siblings and/or grandparents were the only ones (other than the parents) allowed to visit the baby in the NICU and mostly only on Sundays. Eighty-seven and a half percent $(87.5 \%)$ of the mothers felt that they could bond with their babies during pregnancy and $75 \%$ felt that they missed an opportunity to bond with their babies after birth, mostly because they were not allowed to hold their babies for up to 11 days after birth. Most surgeons (75\%) did explain the road ahead but $50 \%$ of the mothers felt that they did not have any emotional support from staff at the hospital.

Three of the mothers completing the survey were diagnosed with anxiety and/or depression after the birth of the baby ( 1 anxiety, 1 depression, and 1 with 
anxiety and depression) by a medical professional (doctor or psychologist). Two of the older children born with EA and TEF were also diagnosed (by a medical professional) and treated for anxiety.

Table 2: Questions about the parents' need for emotional support

\begin{tabular}{|c|c|c|c|}
\hline \multicolumn{4}{|c|}{ DURING THE TIME OF YOUR BABIES SURGERY } \\
\hline $\begin{array}{l}\text { Was there a place for you to sleep next to } \\
\text { your baby? }\end{array}$ & $\begin{array}{l}\text { Did you have a place to } \\
\text { shower or bath in the } \\
\text { hospital? }\end{array}$ & \multicolumn{2}{|c|}{ Could family and siblings visit your baby? } \\
\hline \multicolumn{4}{|c|}{ AFTER YOUR BABIES BIRTH } \\
\hline $\begin{array}{l}\text { Did you feel that you bonded in } \\
\text { pregnancy with your unborn baby? }\end{array}$ & $\begin{array}{l}\text { Did you feel that you } \\
\text { missed a chance to bond } \\
\text { with your baby after birth? }\end{array}$ & \multicolumn{2}{|c|}{$\begin{array}{l}\text { If YES, is this because you could not pick him/her up } \\
\text { in the first few hours after birth or was there another } \\
\text { reason? }\end{array}$} \\
\hline $\begin{array}{l}\text { Did a doctor/surgeon sit down and } \\
\text { explain your baby's condition and the } \\
\text { road ahead? }\end{array}$ & $\begin{array}{l}\text { Did anyone in the hospital } \\
\text { offer you any emotional } \\
\text { support? }\end{array}$ & \multicolumn{2}{|c|}{$\begin{array}{l}\text { If } \mathrm{NO} \text {, do you wish that anyone would have offered } \\
\text { you emotional support? }\end{array}$} \\
\hline $\begin{array}{l}\text { Were you put in contact with other } \\
\text { families with the same condition? }\end{array}$ & \multicolumn{3}{|c|}{ If $\mathrm{NO}$, do you think this would have helped you through this time? } \\
\hline \multicolumn{4}{|c|}{ AFTER YOUR BABIES SURGERY } \\
\hline $\begin{array}{l}\text { Have you ever been diagnosed by a } \\
\text { medical professional (doctor, } \\
\text { psychologist, etc.) with any of the } \\
\text { following conditions? }\end{array}$ & $\begin{array}{l}\text { POST TRAUMATIC } \\
\text { STRESS DISORDER } \\
\text { (PTSD) }\end{array}$ & ANXIETY & DEPRESSION \\
\hline $\begin{array}{l}\text { Has ANYONE ELSE IN THE FAMILY } \\
\text { been diagnosed with any of the following } \\
\text { conditions? }\end{array}$ & $\begin{array}{l}\text { POST TRAUMATIC } \\
\text { STRESS DISORDER } \\
\text { (PTSD) }\end{array}$ & ANXIETY & DEPRESSION \\
\hline $\begin{array}{l}\text { Has your child ever been diagnosed with } \\
\text { any of the following conditions? }\end{array}$ & $\begin{array}{l}\text { POST TRAUMATIC } \\
\text { STRESS DISORDER } \\
\text { (PTSD) }\end{array}$ & ANXIETY & DEPRESSION \\
\hline \multicolumn{2}{|c|}{$\begin{array}{l}\text { Do you think sharing your story with others will help both you and } \\
\text { others? }\end{array}$} & \multicolumn{2}{|c|}{$\begin{array}{l}\text { Do you think an OA and/or TOF support group would } \\
\text { be emotionally helpful? }\end{array}$} \\
\hline
\end{tabular}

Only 1 of the 8 mothers was in contact with other families with children born with EA and found that it helped her with this experience. Six of the remaining 7 agreed that this would have helped them during this emotionally challenging time. All 8 mothers thought that sharing their stories with others would have helped them emotionally and all agreed that an EA and/TEF support group was a good idea with many offering to help with establishing such a group.

There is evidence suggesting that parents of ill or injured children are at risk of developing PTSD.[3] PTSD is a disorder that develops in some people who have experienced a shocking, scary, or dangerous event and is characterized by a cluster of symptoms.[3,4] The 5th edition of the Diagnostic and Statistical Manual of Mental Disorder [DSM-5; American Psychiatric Association, 2013], states that PTSD is comprised of four symptom clusters including intrusion symptoms, avoidance, negative alterations in cognition and mood, and alterations in arousal and reactivity.[5]

Although no specific studies have been performed on parents of children with EA and/or TEF, one study looked at mothers of infants who underwent neonatal surgery.[6] PTSD was found in $20 \%$ of mothers within 6 months to 4.5 years after their neonates had undergone surgery. Caplan found that the symptoms of the mothers were related to their child's current health status, the possibility of future surgeries and whether they received support from the fathers.[6] In our small study we showed that 3 out of 8 mothers suffer from diagnosed mental disorders, which is in keeping with Caplan's article. Caplan concluded that psychological morbidity associated with EA and/or TEF has important implications for clinical practice, namely, if psychological support is offered to parents during the neonatal period and continued as part of long-term follow-up for both parents and the children, the overall outcome is improved, and the bio-psycho-social morbidity decreased.

A research article published in 2016 looked specifically at PTSD in parents of children born with EA and/or TEF.[3] Fifty-four parents participated in the study and $59 \%$ of these parents developed PTSD (mothers more than fathers). In addition, some of the mothers experienced severe anxiety. Early emotional support 
by hospital staff (social worker, trauma counselor, nursing staff familiar with the condition) as well as a support group, might have assisted in the short- and long-term prevention of these mental conditions in the parents. Another contributing factor to developing PTSD might be the failure of appropriate bonding of the parents with the baby due to hospital policy, for example the fact that only 1 of the 8 participants in our study could sleep next to her baby in the NICU. Due to both space problems and strict infection con- trol guidelines, parents are usually not allowed to sleep in most NICUs in South Africa. It is extremely stressful, particularly to the mother not to be with her newborn. We postulate that this might lead to an increasing number of PTSD or anxiety disorders in these parents which might also affect the infant. It is of utmost importance that these present policies need to be critically questioned to their viability and potential harm. More research and larger samples are required to confirm this.

Table 3: Results from the emotional support part of the survey

\begin{tabular}{|l|c|c|c|}
\hline \multicolumn{1}{|c|}{ QUESTIONS } & YES & NO & NOT ANSWERED \\
\hline Is there a place for you to sleep next to your baby? & 1 & 7 & 0 \\
\hline Did you have a place to shower or bathe in the hospital? & 5 & 3 & 0 \\
\hline Could family and siblings visit the baby? & 6 & 2 & 0 \\
\hline Did you feel that you bonded in pregnancy with your unborn baby? & 7 & 0 & 1 \\
\hline Did you feel that you missed a chance to bond with your baby after birth? & 6 & 2 & 0 \\
\hline $\begin{array}{l}\text { Is this because you could not pick him/her up in the first few hours/days after } \\
\text { birth or was there another reason? }\end{array}$ & 6 & 0 & \\
\hline $\begin{array}{l}\text { Did a doctor/surgeon sit down and explain your baby's condition and the } \\
\text { road ahead? }\end{array}$ & 6 & 0 & \\
\hline Did anyone in hospital offered you any emotional support & 4 & 4 & 2 \\
\hline \begin{tabular}{l} 
If NO, do you wish that anyone would have offered you emotional support? \\
\hline Were you put in contact with other families with the same condition?
\end{tabular} & 2 & 0 & 0 \\
\hline If NO, do you think this would have helped you through this time? & 6 & 7 & 2 \\
\hline $\begin{array}{l}\text { Have you ever been diagnosed by a medical professional with ANXIETY, } \\
\text { PTSD, OR DEPRESSION? }\end{array}$ & 2 & 6 & 0 \\
\hline $\begin{array}{l}\text { Have ANYONE ELSE IN THE FAMILY been diagnosed with ANXIETY, } \\
\text { PTSD, OR DEPRESSION? }\end{array}$ & 2 & 6 & 0 \\
\hline $\begin{array}{l}\text { Has your child ever been diagnosed with ANXIETY, PTSD, OR } \\
\text { DEPRESSION? }\end{array}$ & 2 & 6 & 0 \\
\hline Do you think sharing your story with others will help both you and others? & 8 & 0 & 0 \\
\hline Do you think an EA/TEF support group is a good idea? & 8 & 0 & \\
\hline
\end{tabular}

South Africa has not had a formal support group for parents of children born with EA and/or TEF. Support groups aim to provide both parents and children with a forum for sharing similar experiences.[2] This has been proven to reduce stress, anxiety, and later PTSD.[2] In our small and preliminary study, only one mother was in contact with other parents with children with similar diseases, but 6 of the remaining 7 said that they felt that they would have benefited from such contact. This together with the fact that all the mothers felt that a formal support group would be a good idea, suggests that a support group could be essential in providing emotional support to these parents. A formal support group can be a platform where they can share their stories and experience with other parents, who understand them, and this could be an important part of the emotional healing process for these parents.

Although most surgeons (75\%) explained the diagnosis and prognosis to parents, $50 \%$ of participants expressed that they did not receive any emotional sup- port from the hospital staff (mostly in the private sector). It is our personal experience that the private nursing staff are not as often exposed to EA/TEF as staff in the public sector. The fact that they themselves seem not to be able to fully understand the complexity of this condition might prevent them from counselling parents effectively. South African hospitals also lack trauma counsellors and social workers in the private sector. Lastly the lack of psychologists in the private hospitals with the resistance of medical aids to pay for these consultations further worsen this problem. During our personal experience we encountered wonderful doctors and nurses who looked after us, but we had no one that could offer any insight into the road ahead. This is a big problem that will need to be addressed, especially in the South African private sector.

In response to the positive reaction to the questions about the need for a support group, a formal support group for parents and children born with EA and/TEF in South Africa (OATSA) was started in November 
2019. The informal WhatsApp group has grown to a formal non-profit organization with over 50 members from different parts of South Africa. Members from different cultures (Afrikaans, English, Xhosa, and Zulu speaking members) and demographics (public and private sector with members from rural areas to big cities) are represented in this group. The support these members give to each other is overwhelming.

To conclude, often medical professionals look at disease and disease processes from a purely technical point of view. Surgeons ask how they can 'fix' the problem to improve the patient's quality of life. They often forget the other side, namely that parents require emotional support: someone to be there for them and to listen to their experience in hospital and at home. The family needs to be treated and listened to as another "patient". As such they should be included in the overall treatment plan if we intend to improve the quality of life of both the patients and their families. There is a need to develop a multidisciplinary support system in South Africa to aid patients born with EA and their caring families. This

\section{REFERENCES}

1. Faugli A, Bjørnland K, Emblem R, Nøvik TS, Diseth TH. Mental health and psychosocial functioning in adolescents with esophageal atresia. J Pediatr Surg. 2009; 44:729-37. Available from: https://doi.org/10.1016/j.jpedsurg.2008. 09.027.

2. Strobel NA, Adams MC, Rudd C. The role of support groups and ConnectGroups in ameliorating psychological distress. Available from: https://www.researchgate.net/publication/ 333841541_The_role_of_support_groups_and_ConnectGrou ps_in_ameliorating_psychological_distress.

3. Le Gouëz M, Alvarez L, Rousseau V, Hubert P, Abadie V, Lapillonne A, et al. Posttraumatic stress reactions in parents of children with esophageal atresia. PLoS One. 2016; 11:1-10. Available from: https://doi.org/10.1371/ journal.pone.0150760. includes the entire family and is not limited to the mothers but should also include the fathers and siblings. Although we do acknowledge the small sample size of this study as a limitation, we are of the opinion that this preliminary study demonstrates that disease specific support groups could play a major role in the emotional well-being of both the affected children and their families. We further hypothesize that the poor rate of completion of the questions can be linked to the trauma associated with the diagnosis and surgery of the parent's babies during the neonatal period. Further studies are required to explore this in more detail.

\section{Acknowledgements: $\mathrm{Nil}$}

Conflict of Interest: Authors have no conflict of interest.

Source of Support: Nil

Consent to Publication: No clinical figure is being used in this manuscript.

Author Contributions: Author(s) declared to fulfil authorship criteria as devised by ICMJE and approved the final version.

4. NIMH. Post-Traumatic Stress Disorder. Available from: https://www.nimh.nih.gov/health/topics/post-traumaticstress-disorder-ptsd/index.shtml.

5. Pietrzak RH, Tsai J, Armour C, Mota N, Harpaz-Rotem I, Southwick SM. Functional significance of a novel 7 -factor model of DSM-5 PTSD symptoms: Results from the National Health and Resilience in Veterans Study. J Affect Disord. 2015; 174:522-6. Available from: https://doi.org/10.1016/j.jad.2014.12.007.

6. Caplan A. Psychological impact of esophageal atresia: Review of the research and clinical evidence. Dis Esophagus. 2013; 26:392-400. Available from: https://doi.org/10.1111/dote.12056. 